\title{
Investigations of electrophysical monitoring in a full-scale experiment to clean soil contaminated with oil
}

\author{
Sergey Prostov ${ }^{1}$, and Evgeniy Shabanov ${ }^{1 *}$ \\ ${ }^{1}$ T.F. Gorbachev Kuzbass State Technical University, 650000, Str. Vesennyaya 28, Kemerovo, \\ Russian Federation
}

\begin{abstract}
This article presents the main results of the study of electrophysical processes occurring in the zone of electrical processing during the cleaning of soils from oil pollution. The main conclusions are formulated about the processes occurring in the electric processing zone by changing the relative electrical resistance of the soil, which was measured using microprobe sensors. A comparative analysis of the results of a laboratory experiment on the electrochemical cleaning of contaminated soil in a tank is carried out with the results of a full-scale experiment conducted on a plot of a soil mass in real conditions, but artificially contaminated with oil products (gasoline, used oil. Using single measurements of electrical resistivity by microprobe sensors, the spread of the pollutant in the soil was clarified, the relationship between the physical properties of the array and its electrical wire is established conductive properties. Confirmed high efficiency of this type of control in the study of complex processes occurring in the contaminated ground array.
\end{abstract}

\section{Introduction}

More than 4,331.3 million tons of oil is consumed annually in the world. Petroleum products are used in various fields of activity. As a rule, petroleum products obtained by processing crude oil are used. With such a volume of consumption, production, transportation and refining, part of the oil and oil products creates a huge problem of our time - environmental pollution [1-4]. As a rule, oil and oil products fall into water (rivers, lakes, seas, groundwater, etc.) and soil (soils). Hydrosphere pollution is a more toxic effect on nature, but in the long run, soil pollution can have a much detrimental effect on nature. According to information and technical guides on the best available technologies, oil and its refined products belong to the list of marker substances that are found in all industrial facilities, for example, in Kuzbass oil and its refined products (fuel, combustible lubricants) are very common [5].

There are various classifications of methods for cleaning contaminated soils. The following approaches were formed by the impact mechanism: removal of oil from the soil, including by removing contaminated soil from the array; reduction of toxicity

\footnotetext{
${ }^{*}$ Corresponding author: shabanovea@kuzstu.ru
} 
(decontamination) of petroleum products inside the soil mass without its extraction; the creation of structures in the soil mass that impedes the spread of oil and oil products localization $[6,7]$. According to the principle of the interaction of petroleum products in the massif during cleaning, the methods of soil recovery are divided into four types: physical, chemical, physico-chemical [8, 9], biochemical [10-12].

Currently, a promising modern method of cleaning is being developed - electrochemical treatment, which is based on the effect of electricity on the soil mass, together with the solvent substance. This method is most effective for dispersed low-permeable soils in which electroosmosis effectively flows. During the electrochemical treatment of clay low permeability soils, the following processes occur:

- thermal effect from heating by electricity, which leads to changes in the phase state of oil products;

- interaction of a solvent substance with pollution, creating lighter and liquid fractions with their subsequent pumping.

In a contaminated soil mass under the electric current voltage, changes in its structural state occur, as well as physical properties [13], including electrically conductive and dielectric characteristics $[14,15]$.

In the laboratory of electrophysical control, KuzSTU a complex of studies and experiments was conducted on the electrochemical cleaning of soil contaminated with oil products. During this set of experiments, a one-dimensional physical model and a threedimensional model were investigated. Patterns of changes in the physical and conductive properties of soils during array cleaning were obtained. When conducting electrochemical cleaning of the soil in a one-dimensional model, the phenomenon of coalescence of oil particles and soil particles in the pores of the array was established, which, according to the results, led to an increase in the particle size of the soil, which occurred simultaneously with changes in the measured electrical resistance of the soil mass. When conducting electrochemical cleaning of the soil in a three-dimensional physical model, it was found that the previously obtained results in the one-dimensional model are reliable and soil particles with oil products in the pores of the array turn into a solid cohesive state, an increase in the electrical resistivity (resistivity) of the soil and a decrease in humidity. The results of these laboratory experiments on one-dimensional and three-dimensional physical models are described in detail in $[16,17]$.

Various conditions for laboratory research are quite different from the real ones in the array of soil under the open sky. The main differences in laboratory and field studies are as follows:

- in the laboratory installation there is no interaction of the adjacent soil massif with the electric treatment zone;

- in the laboratory on the model there is no possibility of studying processes in the processing zone by means of integrated geophysical control;

- the volume in the laboratory model is limited to surfaces that have insulating properties and distort physical fields during electrical resistance measurements and processing;

- in the laboratory there is no effect of atmospheric effects on the physical and electrical properties of the array;

- in the laboratory setup, the number of electrodes used is 2 , in real conditions, many electrodes are used during processing, and there is a mutual influence of the electrode pairs on each other and the nearby array.

Using field studies, you can verify the reliability of previously obtained results and patterns in laboratory models. 


\section{Method of research}

During a full-scale experiment, a local area with a clay massif was prepared on a special territory, where it is possible to study the processes occurring in contaminated soil during electrochemical cleaning.

At the site of the full-scale experiment, the installation of an electric power structure consisting of a power transformer TS-40 and a rectifier-converter was performed to transform alternating current into direct current. Special tanks were mounted for transporting and storing pollutants - oil products (used oil and AI-80 gasoline).

Direct current from the electric power plant to the electrodes was supplied through electric wires of the type KG $4 \times 25-0.66$. The rectifier-converter regulates the strength of the supplied current from 0.1 to $40 \mathrm{~A}$ and the voltage from 0 to $360 \mathrm{~V}$. Processing was carried out continuously. As electrodes, metal pipes with a diameter of $57 \mathrm{~mm}$ were used with perforations below ground level. The depth of immersion of the electrodes in the soil was $2300 \mathrm{~mm}$. To conduct a full-scale experiment on electrochemical cleaning, an orderly scheme of connecting pipes - electrodes was applied, so that the edges of the cathode, and in the middle - the anode. The distance between the rows of electrodes is $1.2 \mathrm{~m}$, and between the opposite polarity electrodes is $0.6 \mathrm{~m}$.

The natural clay massif was artificially contaminated with gasoline and used oil. In the soil during the preparation of the experiments, holes were made with a diameter of $12 \mathrm{~mm}$ and a depth of $0.7 \mathrm{~m}$. The distances between the holes were $80-100 \mathrm{~mm}$, they were evenly distributed over the entire area. AI- 80 gasoline was poured into the holes obtained on part of the site, and used automobile oil was poured on the other part of the site. Pollutants were absorbed from the hole through the bottom and sides into the soil, so that a pollution zone formed up to $2000 \mathrm{~mm}$ deep, which is similar to the existing zones resulting from technological disasters (Fig. 1).

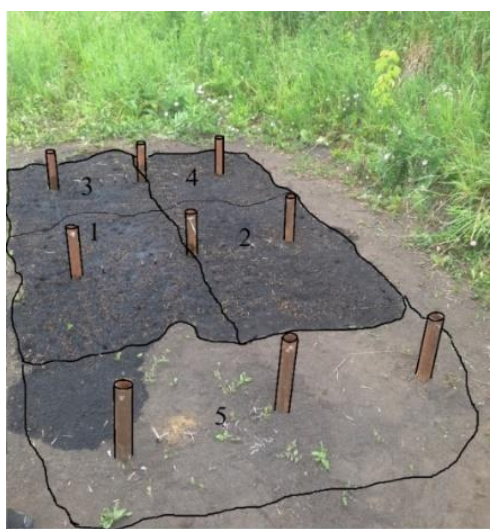

Fig. 1. Type of pollution zone and electrochemical treatment zone: 1 - array contaminated with waste oil; 2 - an array contaminated with gasoline; 3 - array contaminated with waste oil treated with a solvent; 4 - array contaminated with gasoline with solvent treatment; 5 - pure clay massif

At each of the periods of the experiment, constant electrophysical monitoring of soil characteristics in the zone of electrochemical processing was performed. Monitoring included geological engineering surveys and geophysical monitoring. Electrophysical control was carried out locally with the help of microsensors of electrical resistivity and integral with the help of electrical sensing and georadar. Below we will discuss the results obtained with the help of microsensors of electrical resistivity. Using a KP-2 logging tool 
and UES microsensors, changes in the true resistivity of the soil mass were monitored with a step of $0.1-0.15 \mathrm{~m}$

Before pollution began, an initial measurement of the true resistivity was performed before pollution. Immediately after pollution, a single measurement of the true resistivity was performed before the electrical treatment of contaminated soil. With the beginning of electrochemical cleaning, true electrical resistivity measurements were performed twice a day. At the time of the measurements, the electric power plant was disconnected from the electric current. Upon completion of the electrochemical cleaning of the massif at characteristic points (clean soil contaminated with gasoline and waste oil), samples were taken and its density, humidity, porosity and particle size distribution were determined. The article [18] provides an analysis of the main results of the study of physical and mechanical properties.

Within 168 hours, electrochemical soil treatment was carried out by electric current. The current consumption for one pair of electrode tubes left more than $600 \mathrm{Ah}$. The processing zone was divided into 5 zones:

1 - plot of soil from uncontaminated clay, which was treated with electroosmosis without introducing solvents and liquids into the electrodes. This site was a reference for comparing the results obtained on a clean array with the results obtained on contaminated soil;

2 - the second section of the array was contaminated with used oil. Electrochemical cleaning was carried out by electric current without introducing a solvent into the electrodes into the active substance;

3 - the third section of the array was contaminated with AI- 80 gasoline. Electrochemical cleaning was carried out by electric current without introducing a solvent into the electrodes into the active substance;

4 - the fourth section of the array was contaminated with used automobile oil. Electrotreatment was carried out by electric current with the simultaneous introduction of an active substance - a solvent (Hexane-N) into the electrodes. The active substance was poured into the electrode (anode) at times $\mathrm{t}=48$ and 60 hours after the start of treatment in a volume of 4 liters at a time.

5 - the fifth section of the array was contaminated with AI-80 gasoline. Electrotreatment was carried out by electric current with the simultaneous introduction of an active substance - a solvent (Hexane-N) into the electrodes. The active substance was poured into the electrode (anode) at times $t=48$ and 60 hours after the start of treatment in a volume of 4 liters at a time.

The schedule for changing the power plant mode is shown in Fig. 2.

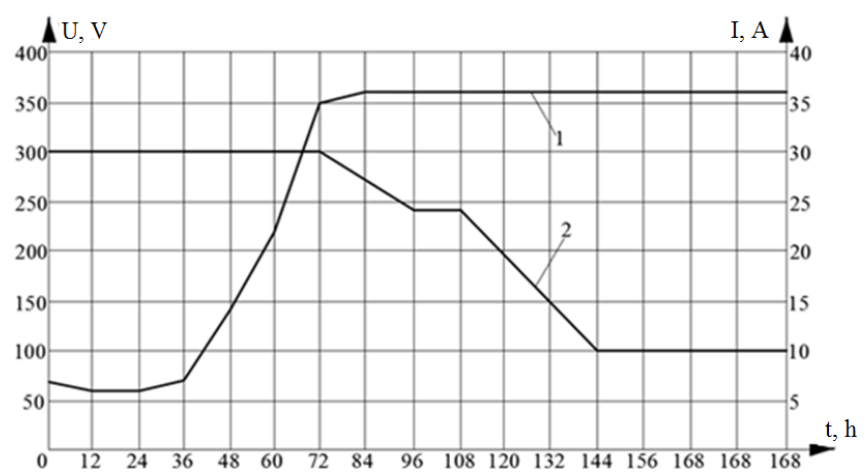

Fig. 2. Change in voltage $U$ (1) and current strength I (2) during electric processing time $t$ 


\section{Results and Discussion}

The main results were obtained by measuring the electrical resistivity at the points of the soil mass using microprobe sensors installed in special holes in the massif to a depth of 700 $\mathrm{mm}$. In this study, true electrical resistivity is the main electrophysical parameter. The method of microprobe sensors is implemented using 4-electrode buried microsensors with an electrode spacing of $10 \mathrm{~mm}$. In total, 25 microprobe sensors were mounted in the installation, 5 pcs for each pair of electrodes, their layout is decent.

Measurements of electrical resistivity were carried out with direct current using a special logging tool KP-2, developed at KuzSTU. According to the measurement results, graphs of changes in the electrical resistivity $\rho$ were plotted along the main axes of the electrode installation during electrochemical treatment, at a certain current consumption.

The main results characterizing the processes of spatio-temporal changes of the present electrical resistivity of soils, obtained thanks to the microsensor system, are shown in Figs. 3 and 4.
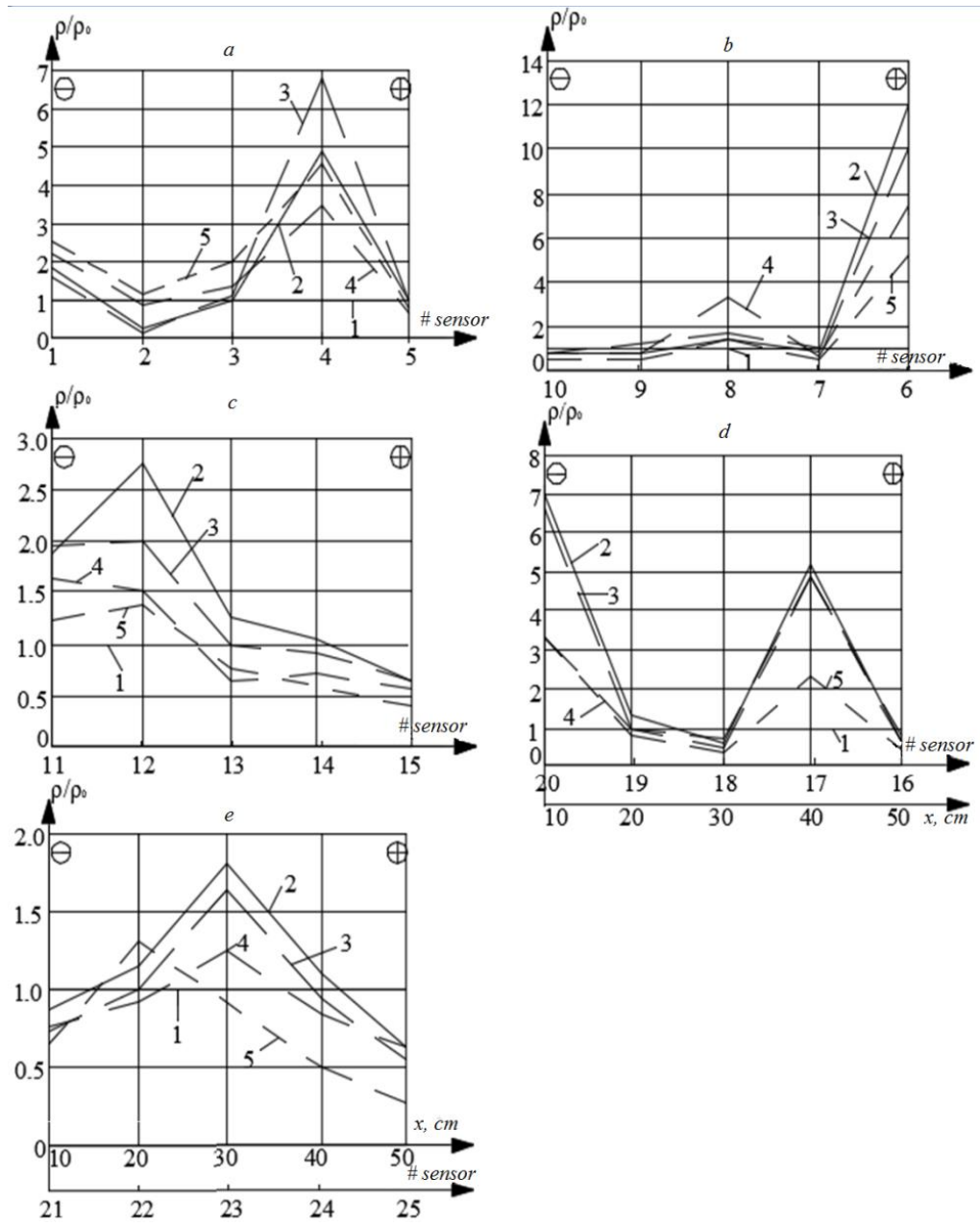

Fig. 3. Relative change in resistivity of soil during electric treatment of clean soil (a), soil contaminated with used oil (b), gasoline (c), used oil with solvent treatment (d), gasoline with solvent treatment (e): 1 - before contamination; 2 - start of processing; 3 - processing time $t=24$ hours; 4 - 48 hours; 5 - $168 \mathrm{~h}$ 

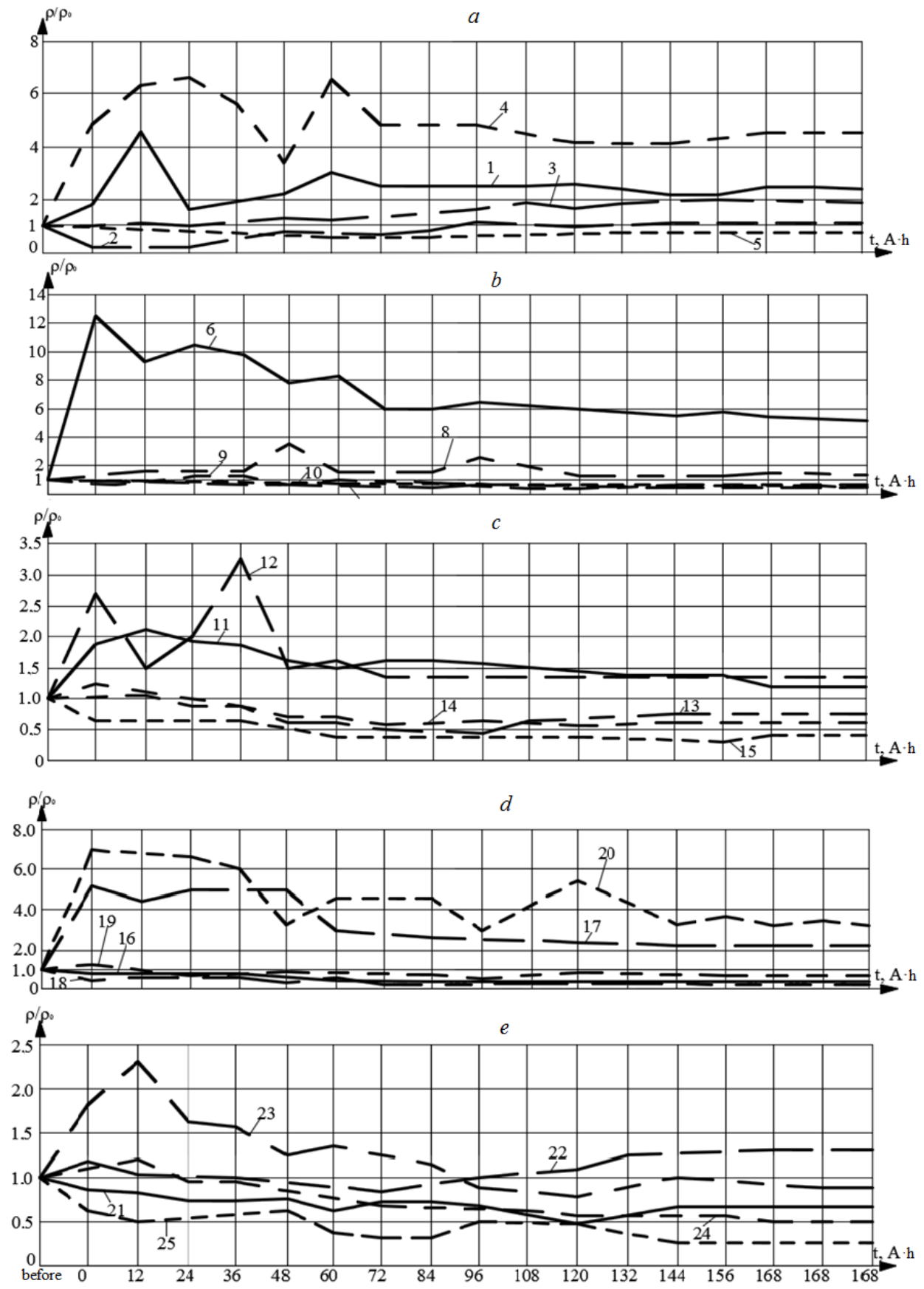

Fig. 4. Relative change in soil resistivity during electrochemical treatment of clean soil (a), soil contaminated with used oil (b), gasoline (c), used oil with solvent treatment (d), gasoline with solvent treatment (e) depending on current consumption: 1 - 25 - numbers of microsensors 
The following is an analysis of the main results of the experiment obtained by measuring resistivity with sensors. As a result of the analysis, the following conclusions were obtained:

- in unpolluted soil (Fig. 3a), moisture is gradually transported from the cathode to the anode (electroosmosis), accompanied by a decrease in the resistivity at the place of moisture concentration and an increase in resistivity in the electric drainage zone, while the anode drainage zone is twice as large as the moisture saturation zone. These zones are formed 24 hours after the start of the experiment on electrochemical processing;

- in the soil flooded with spent oil (Fig. 3b) there was also a progressive movement of liquids, accompanied by changes in resistivity, while an oil accumulation zone forms on the anode, as evidenced by a significant increase in resistivity within the positive electrode, while a section with a reduced resistivity value is based on the cathode, which means a decrease in the oil content in this zone and a greater amount of moisture, because it has a lower electrical resistance;

- there is a progressive movement of the liquid phase in the soil contaminated with waste automobile oil (Fig. 3b), which is accompanied by a change in the resistivity, while a concentration zone of the pollutant is created on the electrode - anode because the resistivity is high near the anode; near the negative electrode, a section with a reduced resistivity is created, because the contaminant concentration and the accumulation of additional moisture having a lower electrical resistance are reduced in the cathode region;

- in the soil contaminated with gasoline (Fig. 3c), a change in electrical resistance gradually occurs, while on the negative electrode a gas accumulation section is created, because the specific electrical resistance increases constantly, and at the end of the electrochemical treatment, the resistivity decreases because moisture enters the area negative electrode; near the positive electrode, a zone with low resistivity is formed due to a decrease in the concentration of the pollutant in this area;

- when the solvent was supplied to the anode, the liquid propagated into the array and accumulated at the cathode, while a decrease in electrical resistance was observed at the place of dilution of the pollutant and the spread of the solvent; in the soil contaminated with waste oil (Fig. 3d), the moisture gradually moves from the cathode to the anode in the first treatment period without solvent, which leads to a decrease in the resistivity on the positive electrode and an increase on the negative electrode, but after adding the solvent in the pore space, mixing of liquids (moisture, solvent and pollutant), which leads to a decrease in resistivity in the areas of accumulation of liquefied solution and increase it in areas of the array, where the process of dilution due to lack of solvent is not occurred; near the cathode, after the addition of the solvent, the resistivity gradually decreases, which indicates the direction of the flow of the solvent toward the negative electrode;

- in the soil mass contaminated with AI-80 gasoline (Fig. 3d), the pollutant evaporates and moisture accumulates near the electrodes at the first stage of the solvent-free electrochemical treatment, because the resistivity on the electrodes decreases, but after the introduction of the active solvent substance, this process is activated again, as a result, areas with low resistivity are formed near the electrodes due to the concentration of a diluted pollutant mixture and a decrease in the mass of oil product, while the resistivity inside the soil increases due to their time active ingredient - a solvent in the required amount, as well as due to reducing the amount of moisture in the space between the electrodes; a decrease in the resistivity at the cathode indicates that a section of accumulation of liquefied petroleum product is formed near it, which was confirmed organoleptically by traces of the contaminant in the perforation of the electrode tubes, as well as by partial evaporation of the petroleum products.

- all current processes proceed without sharp changes monotonously, without sharp changes simultaneously at almost all points of the control site (Fig. 4). 
Fig. 5 shows graphs for measuring electrical soundings - monitoring schemes for the relative size of the effective resistivity $\rho_{\mathrm{k}}$. These graphs characterize integrally the processes within the entire area of $\rho_{\mathrm{k}}$ the electrochemical treatment between the cathode and the anode, which are used in measurements of resistivity as measuring electrodes.

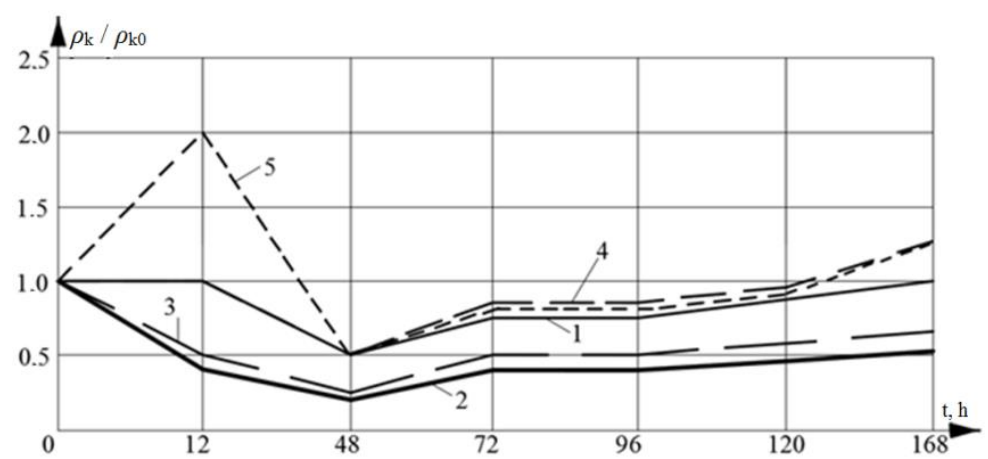

Fig. 5. Change in effective soil resistivity during electrical treatment:

1 - pure clay; 2 - contaminated soil with waste oil; 3 - contaminated soil with gasoline; 4 contaminated soil with waste oil during electrical treatment with a solvent; 5 - contaminated soil with gasoline during electrical treatment with a solvent.

According to the graphs (Figs. 3, 4, 5), we can say that at the time of electric processing for all types of oil products, a general decrease in the resistivity level occurs at the treatment site, which shows a decrease in the concentration of oil products inside the pores of the soil mass. Applying the conditional value of $y \rho_{\mathrm{k}} / \rho_{\mathrm{k} 0}$ as an integral characteristic of the process of decontamination of the pollution zone, it is possible to quantitatively evaluate the change in the coefficient of soil pollution.

\section{Conclusion}

As a result of the research, it can be concluded that the processes of fluid movement occurring under the action of an electric current near the electrodes, which are determined by the resistivity, during electrochemical treatment of contaminated and uncontaminated soil, as well as processing with the additional use of the active substance - Hexane-N, are interconnected, however with all similarities, they have significant differences that arise due to the different conductive physical properties of liquids that are in the pores of the soil (low electric resistance) and the contaminant in the form of waste motor oil, gasoline and the active substance - Hexane-H, with strong dielectric characteristics with oil have different viscosities.

In the zone of electrochemical processing and in the field of electrodes, processes occur that allow you to detail the electrophysical monitoring according to the applied measurement schemes. This type of monitoring has a high resolution.

Thus, geophysical monitoring is an effective complement to geotechnical surveys during the controlled electrochemical cleaning of soil from oil pollution.

The study was conducted as part of grant MK-1212.2020.5 "Geological and geophysical monitoring of the processes of electrochemical cleaning of soil bases of structures from oil pollution". 


\section{References}

1. M. Cehlár, J. Janočko, Z. Šimková, T. Pavlik, M. Tyulenev, S. Zhironkin, M. Gasanov, Resources, 8 (1), 21 (2019)

2. O. K. Tiapkin, A. L. Lozovyi, A. O. Burlakova, P. H. Pihulevskyi, "18th International Conference "Geoinformatics: Theoretical and Applied Aspects", Geoinformatics 2019", 15639 (2019)

3. S. Prostov, E. Shabanov, E3S Web of Conferences Electronic edition, (2018)

4. I. B. Archegova, F. M. Khabibullina, A. A. Shubakov, Contemporary Problems of Ecology, 6, 548 (2012)

5. V. Filipovic, V. Popovic, D. Glamoclija, M. Jaramaz, D. Jaramaz, S. Andelovic, M. Tabakovic, Bulgarian Journal of Agricultural Science, 20, 1 (2014)

6. I. V. Trusei, A. Yu. Ozerskii, V. P. Ladygina, Contemporary Problems of Ecology, 1, $22(2009)$

7. S. I. Kolesnikov, M. G. Zharkova, K. Sh. Kazeev, Russian Journal of Ecology, 3, 157 (2014)

8. V. A. Efremova, E. V. Dabakh, L. V. Kondakova, Contemporary Problems of Ecology, 5, 561 (2013)

9. G. Pop, E. Alexa, T. Iancu, F. Imbrea, A. Laza, Revista de Chimie, 68 (4), 776 (2017)

10. E. L. Vorobeichik, M. V. Kozlov, Russian Journal of Ecology, 2, 89 (2012)

11. V. P. Seredina, M. E. Sadykov, Contemporary Problems of Ecology, 5, 457 (2011)

12. U. Ghosh, S. Chakraborty, Physics of Fluids, 27 (6), 062004 (2015)

13. S. Prostov, E. Shabanov, E3S Web of Conferences IVth International Innovative Mining Symposium, 02013 (2019)

14. E. A. Shabanov, S. M. Prostov, Coal in the 21st Century: Mining, Processing and Safety, 175 (2016)

15. V. A. Korolev, O .V. Romanyukha, A. M. Abyzova, Journal of Environmental Scince and Health. Part A: Toxic, Hazardous Substances and Environmental Engineering, 43 (8), 876 (2008)

16. E. Shabanov, S. Prostov, A. Shadrin, E3S Web of Conferences 2017, C, 01014

17. E. Shabanov, Bulletin of the Kuzbass State Technical University, 2 (120), 20-28 2017 (in Russian)

18. E. Shabanov, S. Prostov, Bulletin of the Kuzbass State Technical University, 6 (118) 35-44 (2016) 